\title{
Article \\ Efficient Synthesis of Mesoporous Nano ZSM-5 Zeolite Crystals without a Mesoscale Template
}

\author{
Changsheng Zhang ${ }^{1, *}$, Kai Fan ${ }^{2}$, Ge Ma ${ }^{1}$, Chi Lei ${ }^{2} \mathbb{D}$, Wei Xu ${ }^{1, *}$, Jie Jiang ${ }^{1, *}$, Bing Sun ${ }^{1}$, Hongxing Zhang ${ }^{1}$, \\ Yunfeng $\mathrm{Zhu}^{1}$ and Song Wen ${ }^{1}$
}

1 Research Institute of Safety Engineering, Sinopec, Qingdao 266100, China; mag.qday@sinopec.com (G.M.); sunb.qday@sinopec.com (B.S.); zhanghx.qday@sinopec.com (H.Z.); zhuyf.qday@sinopec.com (Y.Z.); wens.qday@sinopec.com (S.W.)

2 Department of Chemistry, Zhejiang University, Hangzhou 310028, China; kaif1997@zju.edu.cn (K.F.); leichi@zju.edu.cn (C.L.)

* Correspondence: zhangcs.qday@sinopec.com (C.Z.); xuw.qday@sinopec.com (W.X.); jiangj.qday@sinopec.com (J.J.)

Citation: Zhang, C.; Fan, K.; Ma, G.; Lei, C.; Xu, W.; Jiang, J.; Sun, B.; Zhang, H.; Zhu, Y.; Wen, S. Efficient Synthesis of Mesoporous Nano ZSM-5 Zeolite Crystals without a Mesoscale Template. Crystals 2021, 11, 1247. https://doi.org/10.3390/ cryst11101247

Academic Editor: Pavel Lukáč

Received: 15 September 2021

Accepted: 13 October 2021

Published: 15 October 2021

Publisher's Note: MDPI stays neutral with regard to jurisdictional claims in published maps and institutional affiliations.

Copyright: (C) 2021 by the authors. Licensee MDPI, Basel, Switzerland. This article is an open access article distributed under the terms and conditions of the Creative Commons Attribution (CC BY) license (https:// creativecommons.org/licenses/by/ $4.0 /)$.

\begin{abstract}
Hierarchical zeolites attract people's attention due to their enhanced mass transfer properties in catalytic reactions. The research over obtaining these zeolites in green and efficient methods is of great significance for the current post-treatments and templating strategies tend to be costly for hierarchical zeolite synthesis. In this research, nanosized mesoporous ZSM-5 (SN-ZSM-5) zeolites have been synthesized without the addition of mesoscale templates under highly concentrated conditions. The physicochemical characteristics were systematically investigated by XRD, SEM, N2 sorption, TEM, and NMR. The SEM images showed ZSM-5 crystals with sizes between 50-110 nm were obtained. $\mathrm{N}_{2}$ sorption and high-resolution TEM images gave direct evidence for the hierarchical structure of SN-ZSM-5. The forming mechanism for the hierarchical structure was proposed that the etching effect of the highly alkaline environment for the starting gels played a critical role in the formation of hierarchical structure. Catalytic tests in methanol-to-olefins (MTO) showed the SN-ZSM-5 performed a longer catalyst lifetime and higher propylene selectivity than the conventional ZSM-5 zeolites (C-ZSM-5) obtained from a traditional hydrothermal method. The features of hierarchical structure in the SN-ZSM- 5 crystals and the sustainability for synthesis method could show a promising choice for wide applications of these SN-ZSM-5 zeolites in the future.
\end{abstract}

Keywords: ZSM-5 zeolite; efficient synthesis; hierarchical; nano crystals

\section{Introduction}

Zeolitic materials have always been drawing people's attention due to their important applications in catalysis and adsorption [1-5]. However, zeolitic crystals easily encounter severe coke depositions and fast deactivation as the limitation of mass diffusion in the micropores with a size of less than $2 \mathrm{~nm}$. In order to weaken the mass transfer disadvantage in catalytic reactions, nanosized and hierarchical zeolites have been constructed to obtain better performance in catalytic reactions [6-8]. For instance, nanosized and hierarchical aluminosilicate ZSM-5 zeolites with MFI topological structure could obtain superior catalyst lifetime in the methanol-to-olefin (MTO) reaction, which is regarded as a promising route for light olefins production from natural gas, coal, and biomass with methanol as the intermediate [9-21]. It is pointed out that the lower cokes deposition rate makes direct contributions to the superior catalytic performance of nanosized and hierarchical zeolites.

Traditionally, zeolites are synthesized under hydrothermal conditions. In these cases, the construction of nanosized zeolite usually needs more organic template consumptions to produce more crystal nuclei, leading to the cost increase and large water consumption for zeolite synthesis [1,21-23]. In the early days, the preparations of hierarchical zeolites were usually performed by post-treatments such as high-temperature steaming and acid or 
base leaching [24-26]. In recent years, scientists reported that we could prepare hierarchical zeolites from templating strategies using organic directing agents such as nanosized carbon, polymers, and amphiphilic surfactants $[27,28]$. Both post-treatments and templating strategies are confirmed to be successful for the preparation of hierarchical zeolite crystals, but the relatively high cost still hinders their wide applications in industrial processes. For the hierarchical nano zeolite crystals, it is of great challenge to find proper methods to make them greener and more economical for industrial applications.

Zeolite scientists tried various methods towards the green synthesis of zeolites with excellent catalytic performance. Xiao's group reported that zeolite could be synthesized under solvent-free conditions, which makes a contribution to the much less water solvent consumption and higher production yields for zeolite synthesis $[29,30]$. There have been several reports that mesoporous zeolite could be prepared under solvent-free conditions, but these zeolite crystals are usually on a micron-scale [31,32]. The green and economical acquisition for hierarchical nano zeolites are still of great significance to make further investigations.

Herein, we successfully one-step synthesize nano ZSM-5 crystals with rich mesoporosity inside the crystals without the addition of mesoscale templates and water solvents. The obtained nano ZSM-5 crystals show greatly extended catalyst lifetime and higher propene selectivity in the MTO process compared with the traditional ZSM-5 samples obtained in a hydrothermal method. The forming mechanism of the hierarchical structure is also proposed, which could originate from the etch of starting amorphous phase via the highly alkaline environment. The convenient and efficient synthesis for hierarchical nano ZSM-5 zeolites combined with the excellent catalytic performance provides a sustainable methodology for efficient zeolite catalysts in the future.

\section{Materials and Methods}

\subsection{Materials}

Fumed silica, silica gel, ethyl acetate, potassium carbonate, ethanol, tripropylamine, 1, 6-dibromohexane were purchased from Aladdin. Tetrapropylammonium hydroxide (TPAOH of 40 wt.\%) was supplied by Macklin Reagent $\mathrm{Co} . \mathrm{NaOH}, \mathrm{NaAlO}_{2}$, and methanol were received from Sinopharm Chemical Reagent Co. All the materials were used as received without any further treatments.

\subsection{OSDA Synthesis}

The organic template was synthesized according to published literatures with partial changes [33]. Bis-1, 6-(tripropylammonium) hexamethylene was prepared by exhaustive alkylation of tripropylamine with 1, 6-dibromohexane. Typically, $90 \mathrm{~g}$ of 1, 6dibromohexane, and $110 \mathrm{~g}$ of tripropylamine were dissolved in $150 \mathrm{~g}$ of ethanol, and then $50 \mathrm{~g}$ of potassium carbonate was added. After reflux condensation with the stirring condition under $80^{\circ} \mathrm{C}$ for $24 \mathrm{~h}$, the solution was cooled and filtered to remove potassium salts. Ethanol was removed by rotary evaporation until yielded the semi-solid. The samples were recrystallized with ethyl acetate. After being washed by ethanol and dried under vacuum conditions, the white solid was obtained. The product was converted from the bromide to the hydroxide form (denoted as $\mathrm{ROH}$ ) with an anion exchange resin. Detailly, the white solid was dissolved in a certain amount of deionized water, followed by stirring with excessive anion exchange resin (hydroxide form) for $3 \mathrm{~h}$ under room temperature. The anion exchange process was repeated twice to assure the anion exchange degree. The obtained $\mathrm{ROH}$ solution was concentrated to $19 \mathrm{wt}$ \% by rotary evaporation (denoted as ROH-19).

\subsection{Synthesis of Mesoporous Nano ZSM-5 Zeolite (SN-ZSM-5)}

Nanosized ZSM-5 zeolite was synthesized by grinding the solid raw materials and heated at $180{ }^{\circ} \mathrm{C}$ with molar relations at $300 \mathrm{SiO}_{2} / \mathrm{Al}_{2} \mathrm{O}_{3} / 8.8 \mathrm{OSDA} / 46 \mathrm{Na}_{2} \mathrm{O} / 820 \mathrm{H}_{2} \mathrm{O}$. As a typical run, $0.027 \mathrm{~g}$ of $\mathrm{NaAlO}_{2}$ was added into $3.0 \mathrm{~g}$ of $\mathrm{ROH}-19$. Then the mixed solution was added into a mortar and ground with $3.0 \mathrm{~g}$ of fumed silica and $0.6 \mathrm{~g}$ of $\mathrm{NaOH}$. After 
grinding for 10-20 min, the mixtures were transferred to an autoclave for crystallization. After heating at $180^{\circ} \mathrm{C}$ for $4 \mathrm{~h}$, the samples were completely crystallized. The products were washed with deionized water, centrifuged at room temperature to get zeolite powder, and calcined at $550{ }^{\circ} \mathrm{C}$ for $5 \mathrm{~h}$ to remove the organic templates. The $\mathrm{H}$-form of the samples was prepared from ion-exchange with $\mathrm{NH}_{4} \mathrm{Cl}$ solution $(1 \mathrm{M})$ at $80^{\circ} \mathrm{C}$ for $2 \mathrm{~h}$, and this procedure was repeated twice followed by calcination at $550{ }^{\circ} \mathrm{C}$ for $5 \mathrm{~h}$ again. The obtained samples were designed as SN-ZSM-5.

\subsection{Synthesis of Conventional ZSM-5 Zeolite (C-ZSM-5)}

The conventional ZSM-5 zeolite was synthesized under hydrothermal conditions with molar relations at $300 \mathrm{SiO}_{2} / \mathrm{Al}_{2} \mathrm{O}_{3} / 117 \mathrm{OSDA} / \mathrm{Na}_{2} \mathrm{O} / 9610 \mathrm{H}_{2} \mathrm{O}$. In a typical run, $0.055 \mathrm{~g}$ of $\mathrm{NaAlO}_{2}$ and $40.0 \mathrm{~g}$ of TPAOH (20 wt.\%) were added into $26.0 \mathrm{~g}$ of distilled water. After fully dissolved, $6.0 \mathrm{~g}$ of solid silica gel was added. After stirring for $4 \mathrm{~h}$, the finally obtained gels were transferred into an autoclave and heated at $180^{\circ} \mathrm{C}$ for $48 \mathrm{~h}$, followed by calcination at $550{ }^{\circ} \mathrm{C}$ for $5 \mathrm{~h}$. The $\mathrm{H}$-form of the samples was obtained by ion-exchange with $\mathrm{NH}_{4} \mathrm{Cl}$ solution $(1 \mathrm{M})$ at $80^{\circ} \mathrm{C}$ for $2 \mathrm{~h}$. The ion-exchange procedure was repeated twice, followed by calcination at $550{ }^{\circ} \mathrm{C}$ for $5 \mathrm{~h}$. The obtained samples were designed as C-ZSM-5.

\subsection{Characterization}

X-ray powder diffraction (XRD) patterns were measured with a Rigaku Smartlab X-ray diffractometer ( $45 \mathrm{kV}, 200 \mathrm{~mA}$ ) (Rigaku, Qingdao, China), step size at 0.02 degree, and counting time at $0.03 \mathrm{~s}$ using $\mathrm{CuK}_{\alpha}$ radiation. The morphology of these samples was observed on Hitachi SU 1510 and Hitachi S4800 scanning electron microscope (SEM) (Hitachi, Qingdao, China). The samples were ultrasonically treated for $30 \mathrm{~min}$ before SEM characterization. High-resolution transmission electron microscopy (HR-TEM) images of the samples were obtained on a JEM-2100F transmission electron microscope (JEOL, Qingdao, China). The calcined samples were dispersed in absolute ethyl alcohol and ultrasonically treated for $20 \mathrm{~min}$ before TEM characterization. ${ }^{29} \mathrm{Si}$ and ${ }^{27} \mathrm{Al}$ MAS NMR spectra were recorded on a Bruker AVANCE ${ }^{\mathrm{III}} 400 \mathrm{M}$ spectrometer. The nitrogen sorption isotherms at the temperature of liquid nitrogen were measured using Micromeritics ASAP 2460 (Micromeritics, Qingdao, China). The $\mathrm{NH}_{4}$-exchanged and calcined zeolite samples were degassed at $200{ }^{\circ} \mathrm{C}$ for $12 \mathrm{~h}$ before being measured at the temperature of liquid nitrogen.

\subsection{Catalytic Tests}

The MTO reaction was carried out with a fixed-bed tubular steel reactor with a length of $30 \mathrm{~cm}$ at atmospheric pressure. After $0.50 \mathrm{~g}$ of catalyst (20-40 mesh) was loaded in the middle of tubular steel between two layers of quartz wool, it was pre-treated in flowing nitrogen at $500{ }^{\circ} \mathrm{C}$ for $2 \mathrm{~h}$ and cooled down to a reaction temperature of $480{ }^{\circ} \mathrm{C}$. Methanol was injected into the catalyst bed using a pump with a weight hourly space velocity (WHSV) of $1.0 \mathrm{~h}^{-1}$. The products from the reactor were analyzed online using an Agilent $6890 \mathrm{~N}$ gas chromatograph equipped with an FID detector (detector temperature at $180^{\circ} \mathrm{C}$, inlet temperature at $180^{\circ} \mathrm{C}$ ) and a PLOT- $\mathrm{Al}_{2} \mathrm{O}_{3}$ capillary column (the temperature is controlled by a temperature program: $80{ }^{\circ} \mathrm{C}$ for $5 \mathrm{~min}$, then increased to $160^{\circ} \mathrm{C}$ with the speed of $10^{\circ} \mathrm{C} / \mathrm{min}$, followed by keeping for $15 \mathrm{~min}$ ). Selectivity towards the products was expressed as the mass percentage of each product among all the detectable products except dimethyl ether.

\section{Results}

Figure 1 shows the $\mathrm{X}$-ray diffraction (XRD) pattern, $\mathrm{N}_{2}$ sorption isotherms, scanning electron microscopy (SEM), and high magnification transmission electron microscopy (TEM) images of SN-ZSM-5 prepared at $180^{\circ} \mathrm{C}$ for $4 \mathrm{~h}$. Figure 1a shows the XRD pattern of the samples, exhibiting the well-resolved peaks with an MFI-type zeolite structure in the range of $5-40^{\circ}$. We could find the characteristic diffraction peaks of MFI topology with 
$2 \theta$ at $7.92^{\circ}(011), 8.79^{\circ}(200), 23.07^{\circ}(501), 23.93^{\circ}$ (303), and $24.41^{\circ}$ (133) [34]. $\mathrm{N}_{2}$ sorption isotherms of the samples (Figure $1 \mathrm{~b}$, the black points represent the adsorption curve and the red points represent the desorption curve) give a steep increase in the curve at the relative pressure at $10^{-6}<\mathrm{P} / \mathrm{P}_{0}<0.01$, which is due to the rapid filling of the micropores in the zeolite samples $[35,36]$. It is worth noting that an apparent gradual increase can be observed at the relative pressure of $0.01-0.9$, suggesting there may be mesopores in these samples. It has been reported the hierarchical structure in zeolite crystals would give advantages to the mass transfer and longer catalyst lifetime in catalytic reactions [6-8]. In addition, a fast increase with relative pressure higher than 0.9 can also be observed, which is likely related to the agglomeration of zeolite crystals. Accordingly, the obtained ZSM- 5 zeolite gives BET surface area at $386 \mathrm{~m}^{2} / \mathrm{g}$, micropore volume at $0.099 \mathrm{~cm}^{3} / \mathrm{g}$, and mesopore volume at $0.176 \mathrm{~cm}^{3} / \mathrm{g}$. Figure $1 \mathrm{c}$ shows the high magnification SEM image of SN-ZSM-5. Clearly, the obtained SN-ZSM-5 gives nanocrystals with sizes ranging 50-110 nm measured from more than 100 zeolite particles [37]. Figure 1d shows the high magnification TEM image of SN-ZSM-5. Interestingly, we could directly observe the presence of mesopores with pore sizes ranging 5-15 $\mathrm{nm}$ inside the zeolite crystals. The BET and micropore volume values of the obtained zeolite crystals are relatively small compared to standard ZSM- 5 zeolites, which may be caused by the effect of nano size and internal mesopores, as previously reported $[38,39]$. These results agree with the $\mathrm{N}_{2}$ sorption information. XRD pattern, SEM images, and $\mathrm{N}_{2}$ sorption isotherms of C-ZSM- 5 and TEM image of SN-ZSM- 5 with higher magnification are shown by Figures S1-S4.
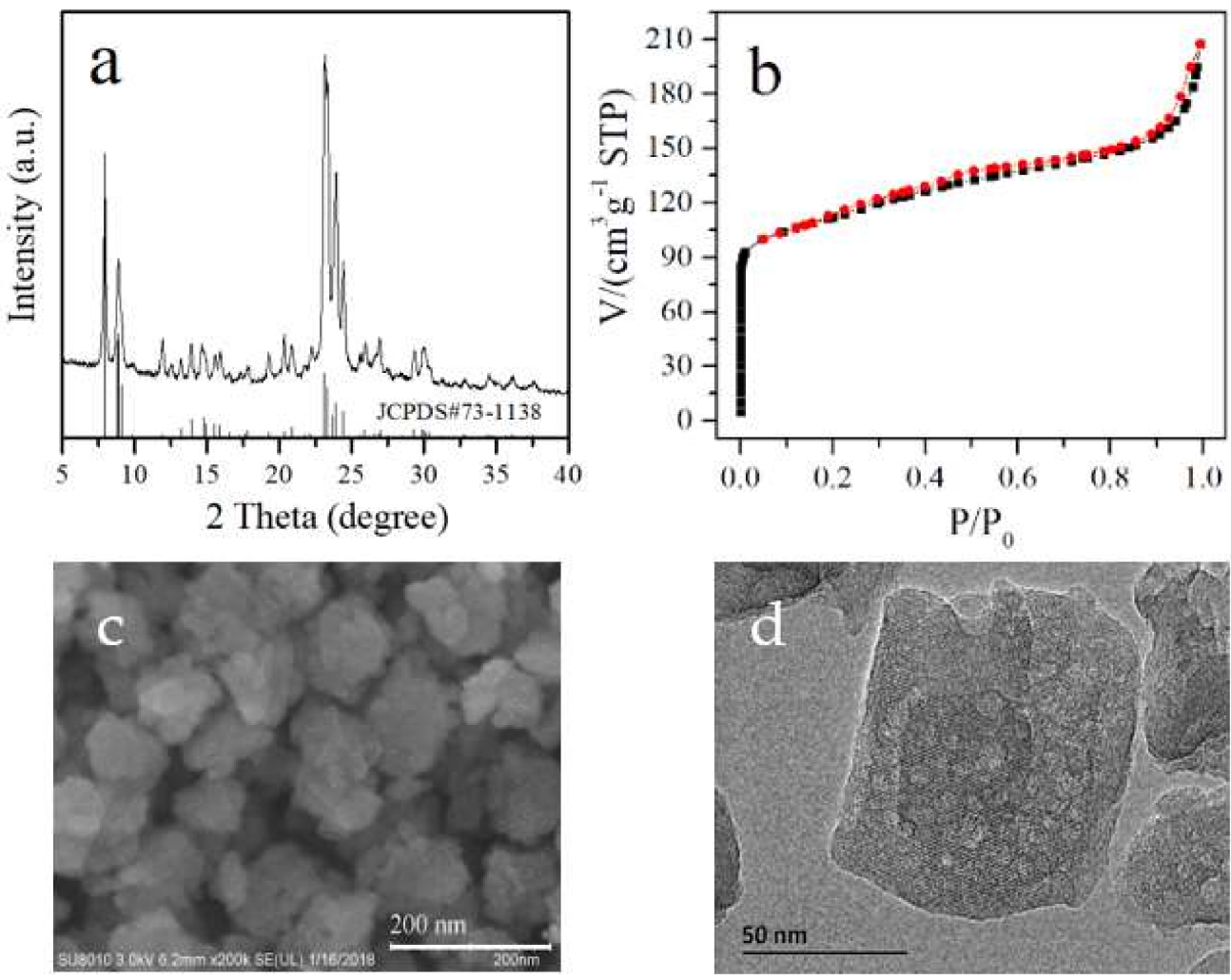

Figure 1. (a) XRD pattern, (b) $\mathrm{N}_{2}$-sorption isotherms, (c) SEM image, and (d) high magnification TEM image of obtained SN-ZSM-5 zeolite.

Normally, the acid sites in zeolites originate from the Al species in the zeolite framework [36]. Figure 2 shows the ${ }^{29} \mathrm{Si}$ and ${ }^{27} \mathrm{Al}$ MAS NMR spectra of SN-ZSM-5. The ${ }^{29} \mathrm{Si}$ spectrum (Figure 2a) gives significant signals centered at $-113 \mathrm{ppm}$, representing the $\mathrm{Si}(\mathrm{Si}$, $\mathrm{Al}) 4$ in the zeolite framework. The ${ }^{27} \mathrm{Al}$ spectrum (Figure $2 \mathrm{~b}$ ) gives a sharp band at about $58 \mathrm{ppm}$ associated with the tetrahedrally coordinated $\mathrm{Al}$ species in the zeolite framework. 
These results indicate the high crystallinity of SN-ZSM-5 zeolite. The ${ }^{29} \mathrm{Si}$ and ${ }^{27} \mathrm{Al}$ MAS NMR spectrum of C-ZSM-5 samples are shown in Figure S5.
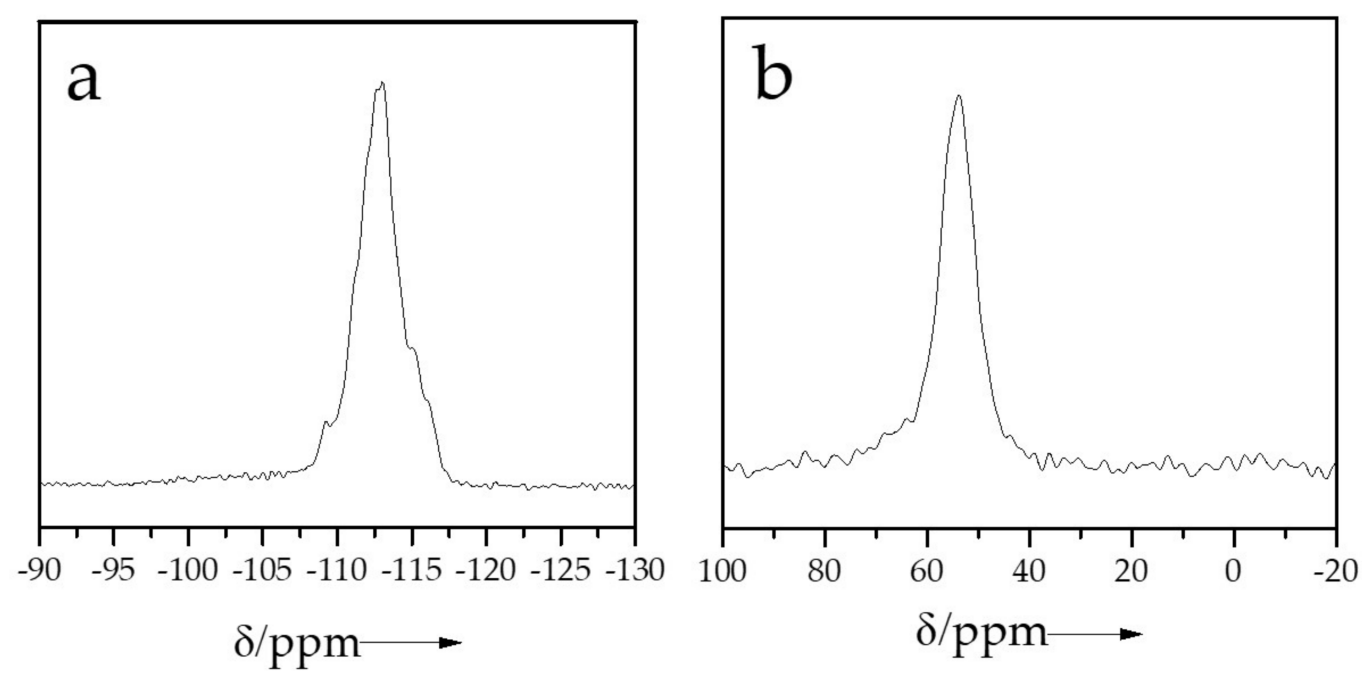

Figure 2. (a) ${ }^{29} \mathrm{Si}$, and (b) ${ }^{27} \mathrm{Al}$ MAS NMR spectrum of SN-ZSM-5 samples.

Figure 3 shows the dependence of methanol conversion in time over SN-ZSM-5 and C-ZSM-5 catalysts in MTO, which is regarded as the most promising method to obtain light olefins in non-petrochemical routes. The MTO reaction has been proposed as a dualcycle mechanism, where the methylbenzenes and olefins serve as the intermediate species. According to this mechanism, fast mass transfer properties would be of great significance for the preparation of highly efficient MTO catalysts [40,41]. Remarkably, the SN-ZSM-5 catalyst exhibits a greatly extended catalyst lifetime as long as $147 \mathrm{~h}$ (Figure 3b), while CZSM- 5 couldn't give full methanol conversion at $43 \mathrm{~h}$ (Figure 3a). Table 1 gives the product selectivities over these two catalysts at a reaction time of $1.0 \mathrm{~h}$. SN-ZSM-5 and C-ZSM-5 both give high selectivity for light olefins (ethylene, propylene, and butylene). But SN-ZSM5 performs higher propylene selectivity at $42.4 \%$, lower selectivity for ethylene (15.7\%), and similar selectivity for butylene (12.6\%), while C-ZSM-5 gives product selectivity for ethylene, propylene, and butylene at $20.1,39.7$, and $12.8 \%$, respectively. In addition, we test the TG properties of the two deactivated catalysts. In the temperature range of $450-650{ }^{\circ} \mathrm{C}$, the TG curves of deactivated SN-ZSM- 5 and C-ZSM- 5 catalysts display quite different weight loss at $21.7 \%$ and $4.7 \%$, respectively, shown by Figures S6 and S7. Considering the much longer resistance to deactivation, we could infer the superior anticoke-deposition ability of SN-ZSM-5. Our research shows comparative results with the reported literatures [41-43]. Considering the acidity of zeolites could greatly influence the olefins formation and hydrogenation process in MTO [36-38], we have performed the $\mathrm{NH}_{3}$-TPD curves of the two obtained ZSM- 5 catalysts, shown by Figure 4 . Clearly, both examples give very similar desorption peaks and peak intensities, indicating the two ZSM- 5 zeolites exhibiting quite similar acidic strength. Considering the similar $\mathrm{Si} / \mathrm{Al}$ ratios (SN-ZSM-5 at 121 and C-ZSM-5 at 116 measured by ICP), these catalytic differences in MTO could be reasonably attributed to the different crystal sizes and mesoporosity properties. 


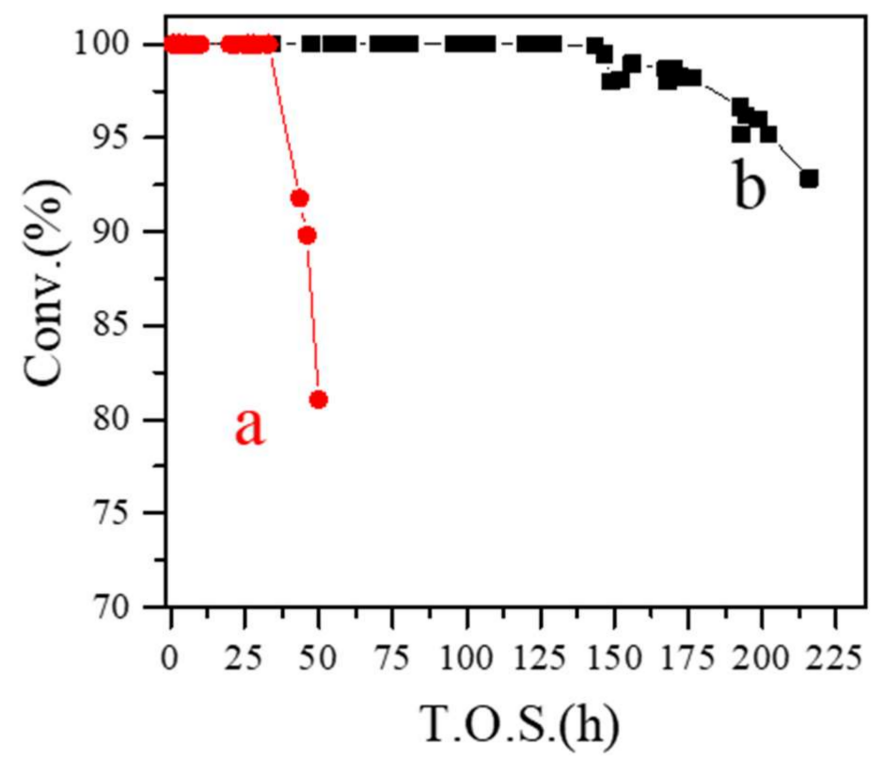

Figure 3. Dependence of methanol conversion on time in MTO reaction over (a) C-ZSM-5 and (b) SN-ZSM-5 catalysts.

Table 1. Product selectivities in MTO over the SN-ZSM-5 and C-ZSM-5 catalysts at reaction time of $1.0 \mathrm{~h}^{\mathrm{a}}$.

\begin{tabular}{ccccccc}
\hline Catalyst & $\mathrm{C}_{\mathbf{1}}$ & $\mathrm{C}_{\mathbf{2}-\mathbf{4}}$ & $\mathrm{C}_{\mathbf{2}}{ }^{=}$ & $\mathrm{C}_{\mathbf{3}}{ }^{=}$ & $\mathrm{C}_{\mathbf{4}}{ }^{=}$ & $\geq \mathrm{C}_{\mathbf{5}}$ \\
\hline SN-ZSM-5 & 2.2 & 8.0 & 15.7 & 42.4 & 12.6 & 19.1 \\
C-ZSM-5 & 2.0 & 9.1 & 20.1 & 39.7 & 12.8 & 16.3 \\
\hline
\end{tabular}

a: Reaction temperature at $480{ }^{\circ} \mathrm{C}$ and WHSV at $1.0 \mathrm{~h}^{-1}$.

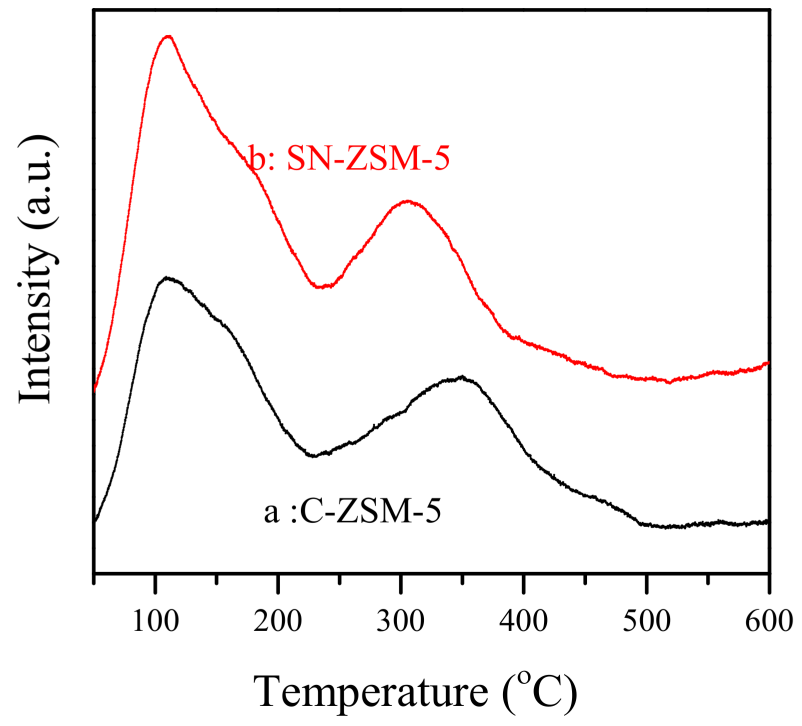

Figure 4. Dependence of $\mathrm{NH}_{3}$-TPD signals on temperature over (a) C-ZSM-5 and (b) SN-ZSM-5 catalysts. The data of $b$ curve is vertically offset for clarity.

In order to further understand the synthesis nature, we investigate the crystallization process of SN-ZSM- 5 with different crystallization times by XRD and SEM technologies, shown in Figure 5A,B. Figure 5(Aa) shows the amorphous phase nature of starting mixtures without crystallization. Correspondingly, we cannot find the zeolite crystals in Figure 5(Ba). As crystallization time increases, the samples with various crystallization times (Figure 5(Ac-Ag)) give characteristic peaks associated with MFI topology except for 
the sample with crystallization time at $60 \mathrm{~min}$ (Figure $5(\mathrm{Ab})$ ), as the crystallization of zeolite requires the induction time. We can find more and more zeolite crystals with sizes ranging 50-110 nm as crystallization time increased (Figure $5(\mathrm{Bb}, \mathrm{Bc}))$, until all the amorphous phase disappears in the SEM images with crystallization time increased to 240 min (Figure 1a). In addition, it is worth noting that these ZSM-5 samples exhibit similar crystallinity with more than $3 \mathrm{~h}$, suggesting that we could efficiently obtain the well-crystallized nanosized ZSM-5 zeolites with rich mesopores inside the zeolite crystals with the crystallization time at 3-4 h. The elemental mapping results of the SN-ZSM-5 with different crystallization times are shown in Figure S8.
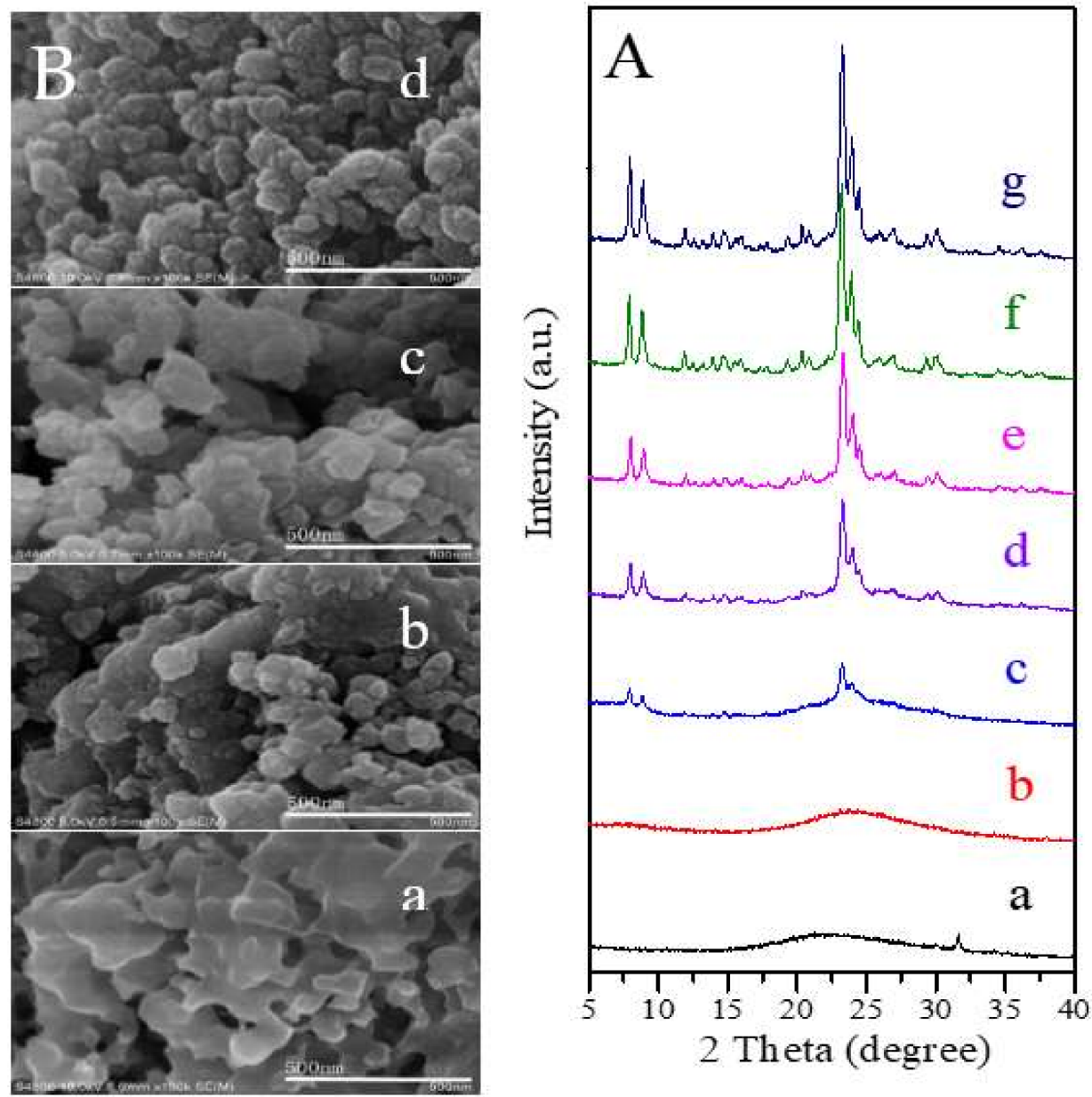

Figure 5. (A) XRD patterns of the SN-ZSM-5 zeolites with crystallization time of (a) 0, (b) 60, (c) 90, (d) 100, (e) 110, (f) 120, (g) $180 \mathrm{~min}$; (B) SEM images of SN-ZSM-5 with crystallization time at (a) 0, (b) 90 , (c) 110 and (d) $180 \mathrm{~min}$.

The synthesis of hierarchical zeolite with no additional mesoscale organic templates is a novel and significant area in the catalysis field. For instance, Yu et al. synthesized the hierarchical porous SAPO-34 zeolites with the assistance of organosilane [41]. Xiao et al. reported the synthesis of hierarchical SAPO-11 molecular, where the released gaseous species were reported as the key factor for the hierarchical structure [33]. Herein, it is interesting to construct the hierarchical structure inside the ZSM-5 crystals without the presence of mesoporous templates. In order to understand the origination of hierarchical structure, we systematically characterized the ZSM-5 zeolites at different crystallization processes with HR-TEM (Figure S9). Accordingly, the proposed mechanism forming the hierarchical zeolite crystals is shown by Scheme 1. In the early stage of gels crystallization, the amorphous fumed silica species are intended to be etched by the highly alkaline environment, considering the zeolite samples are synthesized under highly concentrated 
conditions and sodium hydroxide is added as the alkalinity resource. The etching effect of strong alkalinity for the starting raw materials portrays the role of a sculptor to construct the mesopores inside the amorphous and partially crystallized fumed silica (Figure S9a,b), which is similar to the post-treatment of zeolites to introduce mesopores via alkali [41,42]. As the crystallization time is prolonged, the formed pores are reserved while the amorphous species were continuously transformed to zeolite crystals (Figure S9c). After the samples are fully crystallized, we could obtain the nano ZSM-5 zeolite crystals with hierarchical structures (Figure S9d). In our research, the synthesis performed under a highly alkaline environment originated from the $\mathrm{OH}^{-}$in the template and the addition of $\mathrm{NaOH}$. The strong alkalinity makes contributions to the formation of zeolite crystals with a hierarchical structure. Weakening the alkalinity of the synthetic gels by adding a certain amount of water, we should obtain the zeolite crystal with less or no mesopores. As predicted, we couldn't get the mesoporous ZSM- 5 zeolite samples when water solvent is added, shown in Figures S10-S12. It is reasonable that the highly concentrated conditions play a critical key to obtain the nanosized crystals and hierarchical structure without the presence of the mesoscale templates.

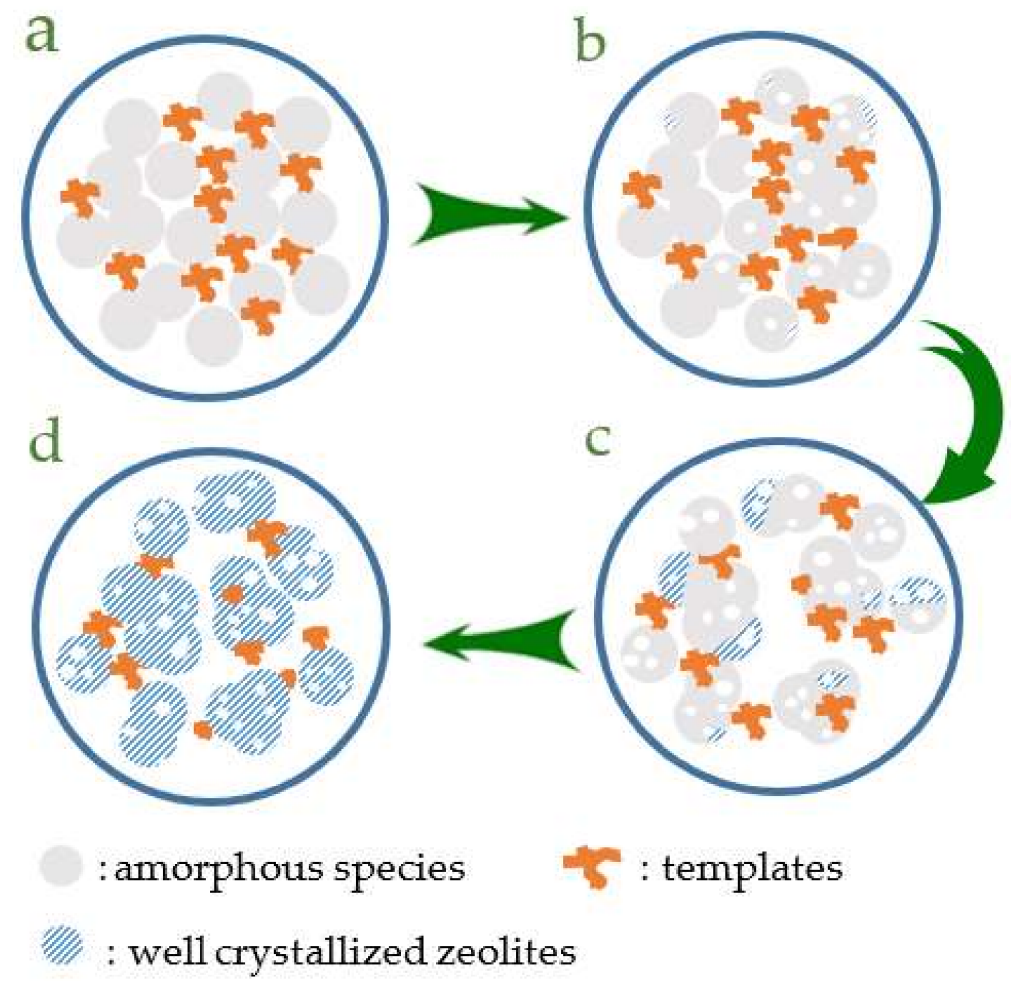

Scheme 1. Formation mechanism for hierarchical structure of the SN-ZSM-5 zeolite (a-d represent the different crystallization periods).

\section{Conclusions}

In summary, we have developed an efficient and convenient method to synthesize hierarchical nano ZSM-5 zeolites (SN-ZSM-5) without the addition of mesoporogens under highly concentrated conditions. Such obtained ZSM- 5 zeolites show high crystallinity and mesoporosity features. Catalytic tests in MTO show that the SN-ZSM-5 shows greatly extended catalyst lifetime and higher propylene selectivity compared with that of the conventional ZSM-5 zeolite obtained by the hydrothermal route. The combination of efficient preparation and excellent catalytic performance of hierarchical nano ZSM-5 zeolite crystals enables the potential application of these obtained zeolite catalysts in the future.

Supplementary Materials: The following are available online at https:/ /www.mdpi.com/article/10 .3390/cryst11101247/s1, Figure S1: XRD pattern of C-ZSM-5, Figure S2: SEM images of C-ZSM-5, 
Figure S3: $\mathrm{N}_{2}$ sorption isotherms of C-ZSM-5, Figure S4: A TEM image of SN-ZSM-5 with different magnification compared with figure 1d, Figure S5: (a) ${ }^{29} \mathrm{Si}$, and (b) ${ }^{27} \mathrm{Al}$ MAS NMR spectrum of C-ZSM-5 samples, Figure S6: TG curve of deactivated SN-ZSM-5 catalysts, Figure S7: TG curve of deactivated C-ZSM- 5 catalysts, Figure S8: Element mapping images of SN-ZSM-5 with crystallization time at (a) 0, (b) 90, (c) 110 and (d) 240 min, Figure S9: HR-TEM images of SN-ZSM-5 synthesized with different crystallization time at (a) 0, (b) 60, (c) 110, and (d) $240 \mathrm{~min}$, Figure S10: XRD pattern of ZSM-5 (calcined) synthesized with $\mathrm{H}_{2} \mathrm{O} / \mathrm{SiO}_{2}$ ratio at 26, Figure S11: SEM images of ZSM-5 zeolite synthesized with $\mathrm{H}_{2} \mathrm{O} / \mathrm{SiO}_{2}$ ratio at 26, Figure S12: $\mathrm{N}_{2}$ sorption isotherms and TEM image of ZSM-5 synthesized with $\mathrm{H}_{2} \mathrm{O} / \mathrm{SiO}_{2}$ ratio at 26 .

Author Contributions: Conceptualization, C.Z.; methodology, C.Z.; validation, C.Z., J.J. and W.X.; formal analysis, C.Z.; investigation, K.F., G.M., C.L., H.Z., Y.Z., S.W. and C.Z.; resources, C.Z., J.J. and W.X.; writing-original draft preparation, C.Z.; writing-review and editing, C.Z., J.J. and W.X.; visualization, C.Z.; supervision, C.Z., J.J. and W.X.; project administration, J.J., B.S. and W.X.; funding acquisition, J.J., B.S. and W.X.; All authors have read and agreed to the published version of the manuscript.

Funding: This work was supported by the National Key R\&D Program of China (2018YFC0808500). The authors would like to thank Xiaoli Fan from Shiyanjia Lab (www.shiyanjia.com, 2021) for the $\mathrm{NH}_{3}$-TPD tests.

Conflicts of Interest: The authors declare no conflict of interest.

\section{References}

1. Valtchev, V.; Tosheva, L. Porous Nanosized Particles: Preparation, Properties, and Applications. Chem. Rev. 2013, 113, 6734-6760. [CrossRef] [PubMed]

2. Meng, X.J.; Xiao, F.-S. Green Routes for Synthesis of Zeolites. Chem. Rev. 2014, 114, 1521-1543. [CrossRef] [PubMed]

3. Shin, J.; Camblor, M.A.; Woo, H.C.; Miller, S.R.; Wright, P.A.; Hong, S.B. PST-1: A Synthetic Small-Pore Zeolite that Selectively Adsorbs $\mathrm{H}_{2}$. Angew. Chem. Int. Ed. 2009, 48, 6647-6649. [CrossRef] [PubMed]

4. Liang, J.; Liang, Z.B.; Zou, R.Q.; Zhao, Y.L. Heterogeneous Catalysis in Zeolites, Mesoporous Silica, and Metal-Organic Frameworks. Adv. Mater. 2017, 29, 1701139. [CrossRef] [PubMed]

5. Gallego, E.M.; Portilla, M.T.; Paris, C.; Escamilla, A.L.; Boronat, M.; Moliner, M.; Corma, A. “Ab initio" synthesis of zeolites for preestablished catalytic reactions. Science 2017, 355, 1051-1054. [CrossRef]

6. Lopez-Orozco, S.; Inayat, A.; Schwab, A.; Selvam, T.; Schwieger, W. Zeolitic Materials with Hierarchical Porous Structures. Adv. Mater. 2011, 23, 2602-2615. [CrossRef]

7. Choi, M.; Na, K.; Kim, J.; Sakamoto, Y.; Tarasaki, O.; Ryoo, R. Stable single-unit-cell nanosheets of zeolite MFI as active and long-lived catalysts. Nature 2009, 461, 246-249. [CrossRef]

8. Tosheva, L.; Valtchev, V.P. Nanozeolites: Synthesis, Crystallization Mechanism, and Applications. Chem. Mater. 2005, 17, 2494-2513. [CrossRef]

9. Kim, J.; Choi, M.; Ryoo, R. Effect of mesoporosity against the deactivation of MFI zeolite catalyst during the methanol-tohydrocarbon conversion process. J. Catal. 2010, 269, 219-228. [CrossRef]

10. Bleken, F.L.; Chavan, S.; Olsbye, U.; Boltz, M.; Ocampo, F.; Louis, B. Conversion of methanol into light olefins over ZSM-5 zeolite: Strategy to enhance propene selectivity. Appl. Catal. A 2012, 447-448, 178-185. [CrossRef]

11. Yang, G.J.; Wei, Y.X.; Xu, S.T.; Chen, J.R.; Li, J.Z.; Liu, Z.M.; Yu, J.H.; Xu, R.R. Nanosize-Enhanced Lifetime of SAPO-34 Catalysts in Methanol-to-Olefin Reactions. J. Phys. Chem. C 2013, 117, 8214-8222. [CrossRef]

12. Mintova, S.; Gilsona, J.-P.; Valtchev, V. Advances in nanosized zeolites. Nanoscale 2013, 5, 6693-6703. [CrossRef]

13. Zhu, Z.G.; Xu, H.; Jiang, J.G.; Wu, H.H.; Wu, P. Hydrophobic Nanosized All-Silica Beta Zeolite: Efficient Synthesis and Adsorption Application. ACS Appl. Mater. Interfaces 2017, 9, 27273-27283. [CrossRef]

14. Tsapatsis, M. Hydrothermal Synthesis of Zeolites with Three Dimensionally Ordered Mesoporous-Imprinted Structure. J. Am. Chem. Soc. 2011, 133, 12390-12393.

15. Wang, Z.; Dornath, P.; Chang, C.C.; Chen, H.; Fan, W. Confined synthesis of three-dimensionally ordered mesoporous-imprinted zeolites with tunable morphology and Si/Al ratio. Micropor. Mesopor. Mater. 2013, 181, 8-16. [CrossRef]

16. Chang, C.C.; Teixeira, A.R.; Li, C.; Dauenhauer, P.J.; Wei, F. Enhanced Molecular Transport in Hierarchical Silicalite-1. Langmuir 2013, 29, 13943. [CrossRef] [PubMed]

17. Liu, D.; Li, G.; Liu, J.X.; Wei, Y.; Guo, H.C. Mesoporous Titanium-Silicalite Zeolite Containing Organic Templates as a Bifunctional Catalyst for Cycloaddition of $\mathrm{CO}_{2}$ and Epoxides. ACS Appl. Mater. Interfaces 2018, 10, 22119-22129. [CrossRef] [PubMed]

18. Zhu, Q.J.; Kondo, J.N.; Ohnuma, R.; Kubota, Y.; Yamaguchi, M.; Tatsumi, T. The study of methanol-to-olefin over proton type aluminosilicate CHA zeolites. Micropor. Mesopor. Mater. 2008, 112, 153-161. [CrossRef]

19. Tian, P.; Wei, Y.; Ye, M.; Liu, Z. Methanol to Olefins (MTO): From Fundamentals to Commercialization. ACS Catal. 2015, 5, 1922. [CrossRef] 
20. Wang, S.; Li, S.Y.; Zhang, L.; Qin, Z.F.; Chen, Y.Y.; Dong, M.; Li, J.F.; Fan, W.B.; Wang, J.G. Mechanistic insights into the catalytic role of various acid sites on ZSM-5 zeolite in the carbonylation of methanol and dimethyl ether. Catal. Sci. Technol. 2018, 8, 3193-3204. [CrossRef]

21. Liu, Z.M. Methanol to Olefins; Science Press: Beijing, China, 2015.

22. Verboekend, D.; Nuttens, N.; Locus, R.; Van Aelst, J.; Verolme, P.; Groen, J.C.; Peirez-Ramirez, J.; Sels, B.F. Synthesis, characterisation, and catalytic evaluation of hierarchical faujasite zeolites: Milestones, challenges, and future directions. Chem. Soc. Rev. 2016, 45, 3331-3352. [CrossRef]

23. Yoshioka, M.; Yokoi, T.; Tatsumi, T. Development of the CON-type Aluminosilicate Zeolite and Its Catalytic Application for the MTO Reaction. ACS Catal. 2015, 5, 4268-4275. [CrossRef]

24. Majano, G.; Darwiche, A.; Mintova, S.; Valtchev, V. Seed Induced Crystallization of Nanosized Na-ZSM-5 Crystals. Ind. Eng. Chem. Res. 2009, 48, 7084-7091. [CrossRef]

25. Tao, Y.; Kanoh, H.; Abrams, L.; Kaneko, K. Mesopore-Modified Zeolites: Preparation, Characterization, and Applications. Chem. Rev. 2006, 106, 896-910. [CrossRef] [PubMed]

26. Groen, J.C.; Zhu, W.D.; Brouwer, S.; Huynink, S.J.; Kapteijn, F.; Moulijn, J.A.; Perez-Ramirez, J. Direct Demonstration of Enhanced Diffusion in Mesoporous ZSM-5 Zeolite Obtained via Controlled Desilication. J. Am. Chem. Soc. 2007, 129, 355-360. [CrossRef] [PubMed]

27. Maria, M.; Sharon, M.; Paolo, C.; David, C.; Javier, P.-R. Mesopore quality determines the lifetime of hierarchically structured zeolite catalysts. Nat. Comm. 2014, 5, 3922. [CrossRef]

28. Chen, L.; Li, X.; Tian, G.; Li, Y.; Rooke, J.C.; Zhu, G.; Qiu, S.; Yang, X.; Su, B. Highly Stable and Reusable Multimodal Zeolite TS-1 Based Catalysts with Hierarchically Interconnected Three-Level Micro-Meso-Macroporous Structure. Angew. Chem. Int. Ed. 2011, 50, 11156-11161. [CrossRef]

29. Xiao, F.-S.; Wang, L.; Yin, C.; Lin, K.; Di, Y.; Li, J.; Xu, R.; Su, D.; Schlogl, R.; Yokoi, T.; et al. Catalytic properties of hierarchical mesoporous zeolites templated with a mixture of small organic ammonium salts and mesoscale cationic polymers. Angew. Chem. Int. Ed. 2006, 45, 3090-3093. [CrossRef] [PubMed]

30. Ren, L.M.; Wu, Q.M.; Yang, C.G.; Zhu, L.F.; Li, C.J.; Zhang, P.L.; Zhang, H.Y.; Meng, X.J.; Xiao, F.-S. Solvent-free synthesis of zeolites from solid raw materials. J. Am. Chem. Soc. 2012, 134, 15173-15176. [CrossRef]

31. Wu, Q.M.; Wang, X.; Qi, G.D.; Guo, Q.; Pan, S.X.; Meng, X.; Xu, J.; Deng, F.; Fan, F.T.; Feng, Z.C.; et al. Sustainable synthesis of zeolites without addition of both organotemplates and solvents. J. Am. Chem. Soc. 2014, 136, 4019-4025. [CrossRef]

32. Zhang, C.S.; Wu, Q.M.; Lei, C.; Pan, S.X.; Bian, C.Q.; Wang, L.; Meng, X.J.; Xiao, F.-S. Solvent-free and mesoporogen-free synthesis of mesoporous aluminosilicate ZSM-5 zeolites with superior catalytic properties in the Methanol-to-Olefins Reaction. Ind. Eng. Chem. Res. 2017, 56, 1450-1460. [CrossRef]

33. Sheng, N.; Xu, H.; Liu, X.L.; Chu, Y.Y.; Han, S.C.; Meng, X.J.; Liu, Y.Q.; Liu, C.G.; Xiao, F.-S. Self-formation of hierarchical SAPO-11 molecular sieves as an efficient hydroisomerization support. Catal. Today 2020, 350, 165-170. [CrossRef]

34. Keoh, S.H.; Chaikittisilp, W.; Muraoka, K.; Mukti, R.R.; Shimojima, A.; Kumar, P.; Tsapatsis, M.; Okubo, T. Factors governing the formation of hierarchically and sequentially intergrown MFI zeolites by using simple diquaternary ammonium structure-directing agents. Chem. Mater. 2016, 28, 8997-9007. [CrossRef]

35. Baerlocher, C.; McCusker, L.B.; Olson, D.H. Atlas of Zeolite Framework Types, 6th ed.; Elsevier: Amsterdam, The Netherlands, 2007.

36. Sel, O.; Kuang, D.; Thommes, M.; Smarsly, B. Principles of Hierarchical Meso- and Macropore Architectures by Liquid Crystalline and Polymer Colloid Templating. Langmuir 2006, 22, 2311-2322. [CrossRef]

37. Liang, T.; Chen, J.; Qin, Z.; Li, J.; Wang, P.; Wang, S.; Wang, G.; Dong, M.; Fan, W.; Wang, J. Conversion of Methanol to Olefins over H-ZSM-5 Zeolite: Reaction Pathway Is Related to the Framework Aluminum Siting. ACS Catal. 2016, 6, 7311-7325. [CrossRef]

38. Thommes, M.; Mitchell, S.; Pérez-Ramírez, J. Surface and Pore Structure Assessment of Hierarchical MFI Zeolites by Advanced Water and Argon Sorption Studies. J. Phys. Chem. C 2012, 116, 18816-18823. [CrossRef]

39. Camblor, M.A.; Corma, A.; Valencia, S. Characterization of nanocrystalline zeolite Beta. Micropor. Mesopor. Mater. 1998, $25,59-74$. [CrossRef]

40. Yang, M.; Fan, D.; Wei, Y.X.; Tian, P.; Liu, Z.M. Recent Progress in Methanol-to-Olefins (MTO) Catalysts. Adv. Mater. 2019, 31, 1902181-1902195. [CrossRef]

41. Yarulina, A.D.; Chowdhury, F.; Meirer, B.M.; Weckhuysen, J.; Gascon, J. Recent trends and fundamental insights in the methanolto-hydrocarbons process. Nat. Catal. 2018, 1, 398-411. [CrossRef]

42. Wang, R.W.; Liu, W.T.; Ding, S.; Zhang, Z.T.; Li, J.X.; Qiu, S.L. Mesoporous MFI zeolites with self-stacked morphology templated by cationic polymer. Chem. Commun. 2010, 46, 7418-7420. [CrossRef]

43. Sun, Q.M.; Wang, N.; Xi, D.Y.; Yang, M.; Yu, J.H. Organosilane surfactant-directed synthesis of hierarchical porous SAPO-34 catalysts with excellent MTO performance. Chem. Commun. 2014, 50, 6502-6505. [CrossRef] [PubMed] 